Supporting Information

\title{
Assessing the performance of Traveling-salesman based Automated Path Searching (TAPS) on complex biomolecular systems
}

\author{
Kun $\mathrm{Xi}^{1,2}$, Zhenquan $\mathrm{Hu}^{1,2}$, Qiang $\mathrm{Wu}^{3}$, Meihan Wei ${ }^{1}$, Runtong Qian ${ }^{1}$ and Lizhe $\mathrm{Zhu}^{1, \mathrm{a})}$ \\ ${ }^{1}$ Warshel Institute for Computational Biology, School of Life and Health Sciences, The Chinese University of \\ Hong Kong, Shenzhen, Shenzhen, Guangdong, 518172, P. R. China.
}

${ }_{2}^{2}$ School of Chemistry and Material Science, University of Science and Technology of China, Hefei, Anhui, 230026, P.R. China.
${ }^{3}$ School of Science and Engineering, The Chinese University of Hong Kong, Shenzhen, Shenzhen, Guangdong, 518172, P. R. China.

a)To whom correspondence should be addressed: zhulizhe@cuhk.edu.cn 


\section{The relation between sequences and secondary structures for protein}

The relationship between sequences and secondary structures for L99A variant of T4 Lysozyme (T4L L99A $)^{1,2}$, the 303-residue fragment used for MEK $1^{3}$ and lymphotactin (Ltn) ${ }^{4,5}$ are shown in Figure S1. Here, the loop-in/loop-out interconversion for MEK1 is mainly restricted in residues 211 to 236, thus a 303-residue length fragment are used to reveal the interconversion mechanism (Figure S1B). The interconversion between Ltn40 and Ltn10 mainly involves a 76-residue fragment ${ }^{4,5}$, which is therefore used to reveal the interconversion mechanism (Figure S1C).

(A) T4L L99A

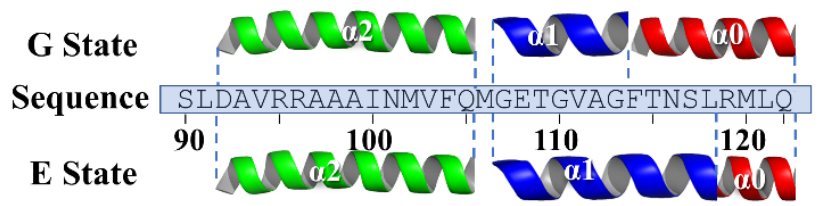

(B) MEK1

(C) LTN
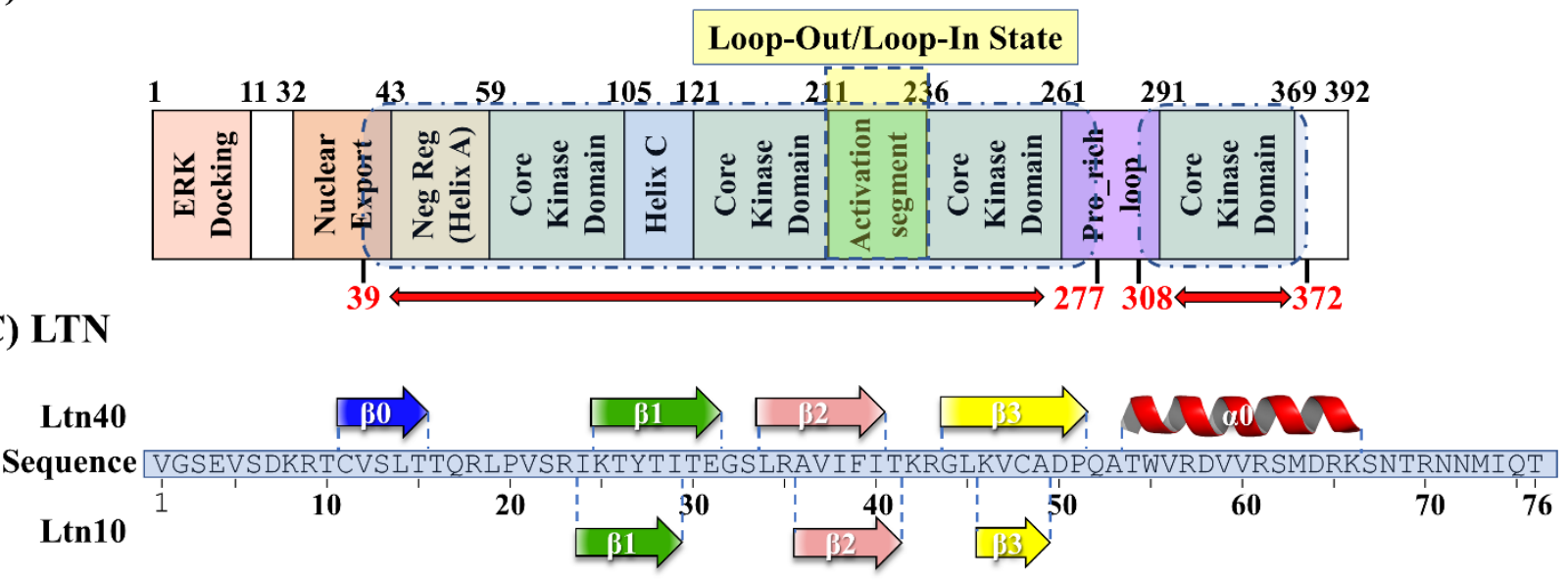

Figure S1: Detailed information for three systems: T4L L99A (A), MEK1 (B) and Ltn (C). (A, B) The relationship between sequences and secondary structures for L99A variant of T4 lysozyme (T4L L99A G State/E State, A) ${ }^{1,2}$ and different states of lymphotactin (Ltn40/Ltn10, C) ${ }^{4,5}$. All the secondary structures are highlighted with same color used in Figure 2. (B) The 303-residue fragment of MAP kinase 1 (MEK1) is highlighted by red arrows: residue 39 to 277 and residue 308 to 372 . The interconversion of MEK1 is mainly the structural change of activation segment, i.e. Loop-Out state and Loop-In state (highlighted with yellow color).

\section{The details of the MD simulation of the three systems}

Table S1 Details of the MD simulation of the three systems in the present work.

\begin{tabular}{|c|c|c|c|c|}
\hline \multicolumn{2}{|c|}{ Systems } & T4L L99A & MEK1 & Ltn \\
\hline \multicolumn{2}{|c|}{ Protein size } & 164-residues/2636 atoms & 303-residues/4814 atoms & 76-residues/1225 atoms \\
\hline \multicolumn{2}{|c|}{ Water } & 10331 & 14227 & 25714 \\
\hline \multirow{2}{*}{ ڤ్ } & $\mathrm{Na}+$ & 10 & 1029 & 0 \\
\hline & $\mathrm{Cl}-$ & 18 & 1827 & 8 \\
\hline \multicolumn{2}{|c|}{$\begin{array}{c}\text { Number of } \\
\text { atoms }^{\mathrm{a}}\end{array}$} & 33657 & 47551 & 78375 \\
\hline
\end{tabular}


${ }^{a}$ The simulation box has been chosen sufficiently large to avoid any contact between periodic images of the systems. This yields a super large box for Ltn, since significant unfolding/refolding (very extended structures) occurred during the transition.

\section{The parameters used in TAPS simulation and analysis methods}

Table S2 The parameters used in TAPS ${ }^{\text {a }}$ optimization for the systems in the present work.

\begin{tabular}{|c|c|c|c|c|}
\hline \multicolumn{2}{|r|}{ Systems } & T4L L99A & MEK1 & Ltn \\
\hline \multicolumn{2}{|c|}{$\begin{array}{c}\text { Sampling time each } \\
\text { iteration }\end{array}$} & $300 \mathrm{ps}$ & $1000 \mathrm{ps}$ & $1000 \mathrm{ps}$ \\
\hline \multicolumn{2}{|c|}{ Temperature } & $300 \mathrm{~K}$ & $300 \mathrm{~K}$ & $300 \mathrm{~K}$ \\
\hline \multirow[t]{2}{*}{$\begin{array}{l}\text { Atoms } \\
\text { set }\end{array}$} & Alignment & $\begin{array}{c}\text { C } \alpha \text { of } \alpha \text {-helices } / \beta- \\
\text { sheets } \\
(\text { except } 92-124)\end{array}$ & $\begin{array}{c}\text { C } \alpha \text { of } \alpha \text {-helices } / \beta \text { - } \\
\text { sheets } \\
\text { (except activation } \\
\text { segment) }\end{array}$ & $\begin{array}{c}\text { C } \alpha \text { of } \alpha \text {-helices } / \beta \text { - } \\
\text { sheets } \\
\text { (only } \beta 2 / \beta 3 \text { ) }\end{array}$ \\
\hline & RMSD & $\begin{array}{l}\text { Heavy atoms of } \\
\text { residue } 92-124\end{array}$ & All Heavy atoms & All Heavy atoms \\
\hline \multicolumn{2}{|c|}{$\begin{array}{c}\text { Tolerant distance for } \\
\text { neighbor nodes }\end{array}$} & $0.8 \AA$ & $1.0 \AA$ & $1.6 \AA$ \\
\hline \multirow{4}{*}{ 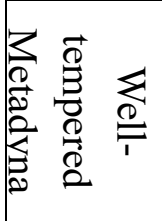 } & Gaussian Height & $0.25 \mathrm{~kJ} / \mathrm{mol}$ & $0.25 \mathrm{~kJ} / \mathrm{mol}$ & $0.25 \mathrm{~kJ} / \mathrm{mol}$ \\
\hline & Gaussian Width & 0.50 & 0.50 & 0.50 \\
\hline & Biasfactor & 10 & 10 & 10 \\
\hline & Length of tMD & $20 \mathrm{ps}$ & $20 \mathrm{ps}$ & $20 \mathrm{ps}$ \\
\hline \multicolumn{2}{|c|}{ Force constant of tMD } & $100,000 \mathrm{~kJ} / \mathrm{mol} / \mathrm{nm}^{2}$ & $100,000 \mathrm{~kJ} / \mathrm{mol} / \mathrm{nm}^{2}$ & $100,000 \mathrm{~kJ} / \mathrm{mol} / \mathrm{nm}^{2}$ \\
\hline
\end{tabular}

${ }^{a}$ Meanings of parameters in Ref. ${ }^{6}$.

\section{The details and results of umbrella sampling for the three systems}

After convergence of the path optimization, the PCV-based umbrella sampling ${ }^{7}$ is performed to obtain the free energy landscape along the minimum free energy path. To ensure sufficient overlap among the umbrella windows between the neighboring nodes, additional nodes were added with an average gap of 0.25 in PCV-s, (Table S3 for details). The result of umbrella sampling for T4L L99A ${ }^{1,2}$, $\mathrm{MEK}^{3}$, and $\mathrm{Ltn}^{4,5}$ were shown in Figures S2-S4, respectively.

Table S3 Details of umbrella sampling ${ }^{7}$ for the systems in the present work.

\begin{tabular}{|c|c|c|c|c|}
\hline \multicolumn{2}{|c|}{ Systems } & T4L L99A & MEK1 & Ltn \\
\hline Node number in final path & 22 & 31 & 335 \\
\hline \multicolumn{2}{|c|}{ Insert gap } & 0.25 & 0.25 & 0.25 \\
\hline $\begin{array}{c}\text { Atoms } \\
\text { set }\end{array}$ & Alignment & $\begin{array}{c}\text { C } \alpha \text { of } \alpha \text {-helices/ } \beta- \\
\text { sheets (except residue } \\
92-124)\end{array}$ & $\begin{array}{c}\text { C } \alpha \text { of } \alpha \text {-helices/ } \beta- \\
\text { sheets (except } \\
\text { activation segment) }\end{array}$ & $\begin{array}{c}\text { C } \alpha \text { of } \alpha \text {-helices/ } \beta \text { - } \\
\text { sheets } \\
\text { (only } \beta 2 / \beta 3 \text { ) }\end{array}$ \\
\cline { 2 - 5 } & RMSD & $\begin{array}{c}\text { Heavy atoms of } \\
\text { residue 92-124 }\end{array}$ & All Heavy atoms & All Heavy atoms \\
\hline $\begin{array}{c}\text { Total number of nodes for } \\
\text { umbrella sampling }\end{array}$ & 88 & 124 & 1340 \\
\hline
\end{tabular}




\begin{tabular}{|c|c|c|c|c|}
\hline \multirow{4}{*}{ 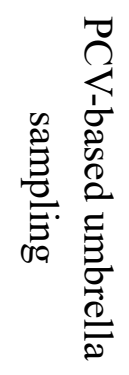 } & $\begin{array}{l}\text { Position for z- } \\
\text { Wall potential }\end{array}$ & $0.0064 \mathrm{~nm}^{2}$ & $0.0100 \mathrm{~nm}^{2}$ & $0.0144 \mathrm{~nm}^{2}$ \\
\hline & $\begin{array}{c}\text { Force constant } \\
\text { for } P C V-z\end{array}$ & $\begin{array}{c}20,000,000.0 \\
\mathrm{~kJ} / \mathrm{mol} / \mathrm{nm}^{2}\end{array}$ & $\begin{array}{c}20,000,000.0 \\
\mathrm{~kJ} / \mathrm{mol} / \mathrm{nm}^{2}\end{array}$ & $\begin{array}{c}20,000,000.0 \\
\mathrm{~kJ} / \mathrm{mol} / \mathrm{nm}^{2}\end{array}$ \\
\hline & $\begin{array}{c}\text { Force constant } \\
\text { for PCV-s } \\
\end{array}$ & $120 \mathrm{~kJ} / \mathrm{mol}$ & $120 \mathrm{~kJ} / \mathrm{mol}$ & $120 \mathrm{~kJ} / \mathrm{mol}$ \\
\hline & Sampling time & $40 \mathrm{~ns}$ & $40 \mathrm{~ns}$ & $2 \mathrm{~ns}$ \\
\hline
\end{tabular}

${ }^{a}$ See Figures S2-S4 for the results of umbrella sampling ${ }^{7}$.

\section{(A) T4L L99A}

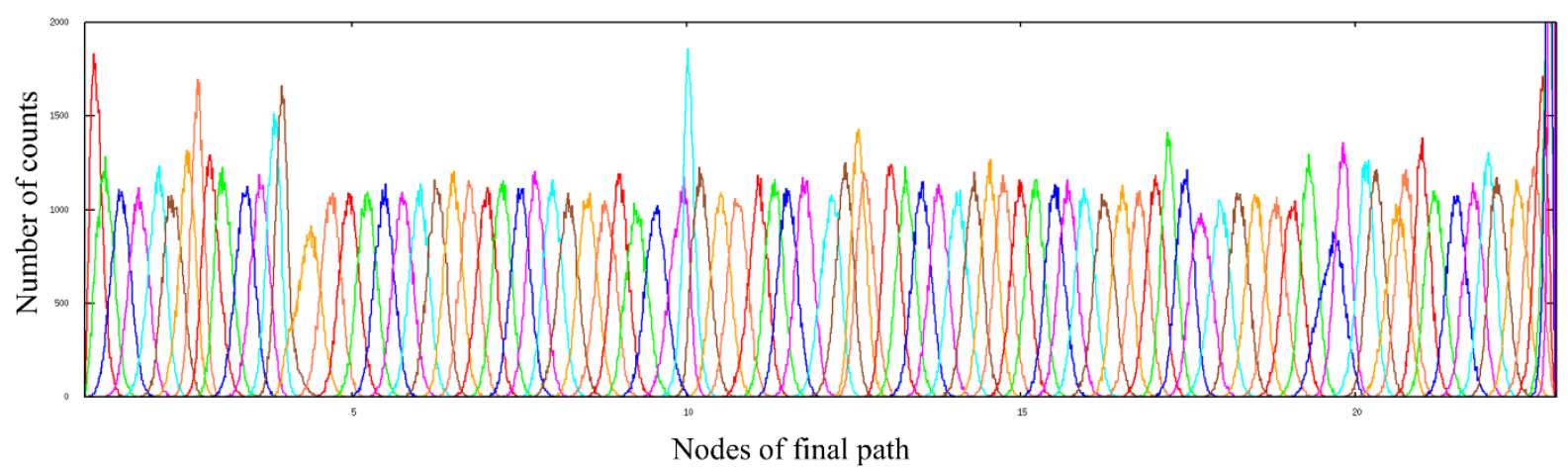

Figure S2: (A) Sample distribution in all windows of the umbrella sampling along the PCV-s for T4L $\mathrm{L} 9 \mathrm{~A}^{1,2}$. The initial $10 \mathrm{~ns}$ of sampling trajectory are disregarded, and only the last $30 \mathrm{~ns}$ of sampling was used for WHAM analysis.

\section{(A) MEK1}

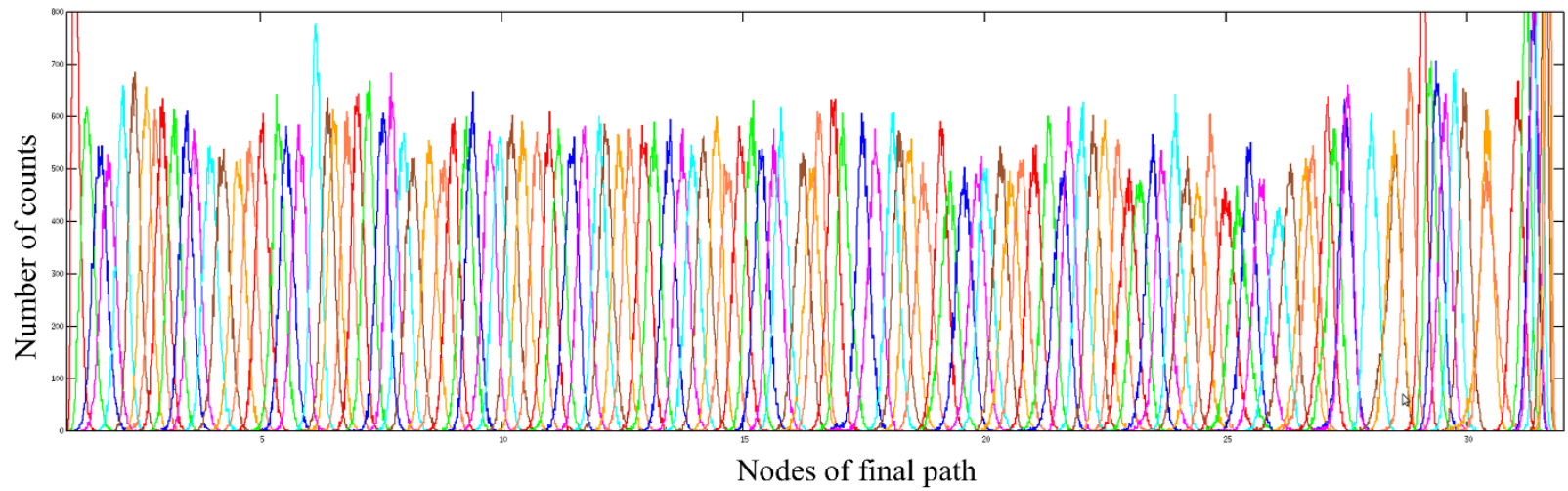

Figure S3: (A) Sample distribution in all windows of the umbrella sampling along the PCV-s for MEK1. The first $10 \mathrm{~ns}$ of sampling was disregarded, only the last $30 \mathrm{~ns}$ of sampling was used for WHAM analysis. 


\section{(A) LTN}

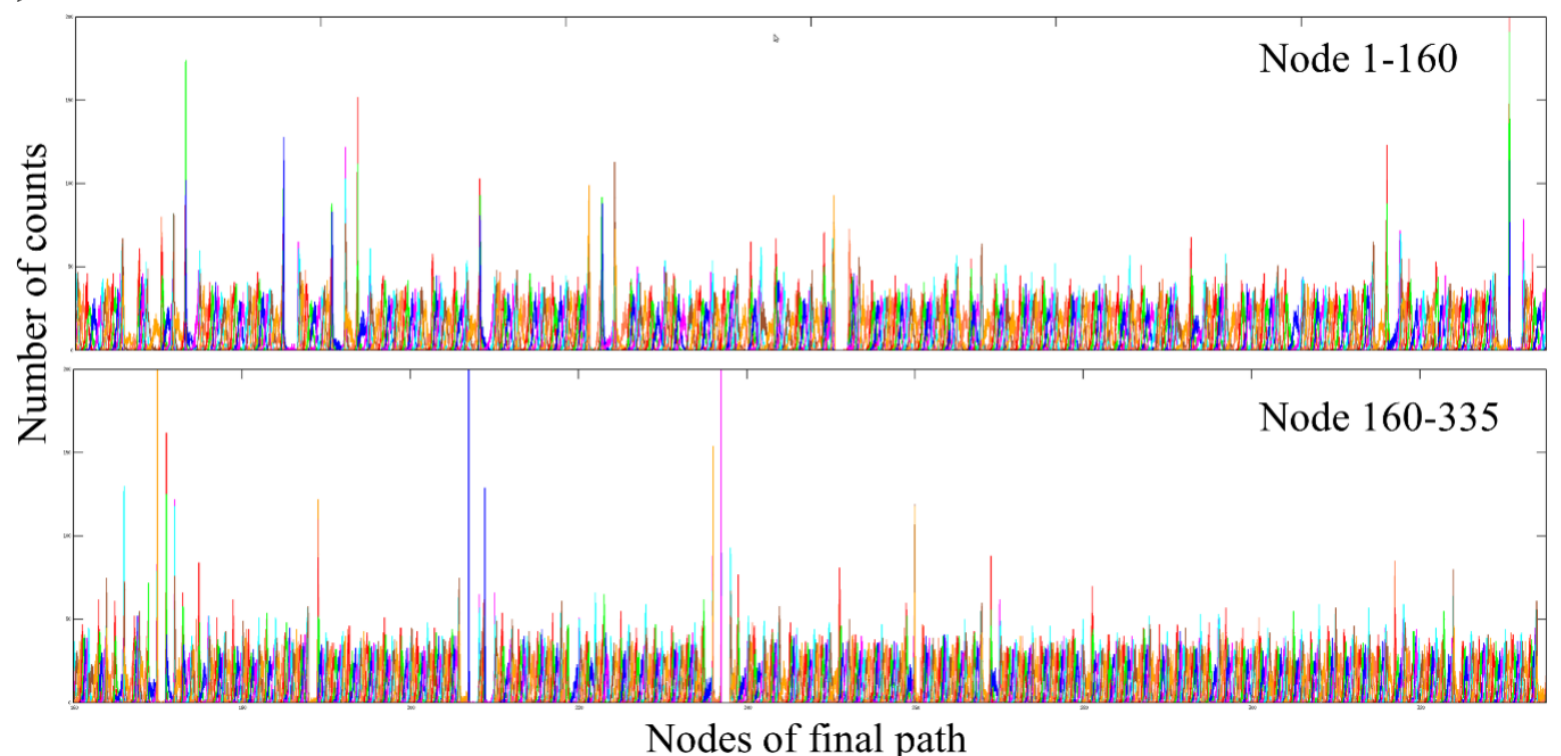

\section{(B) H-bond}

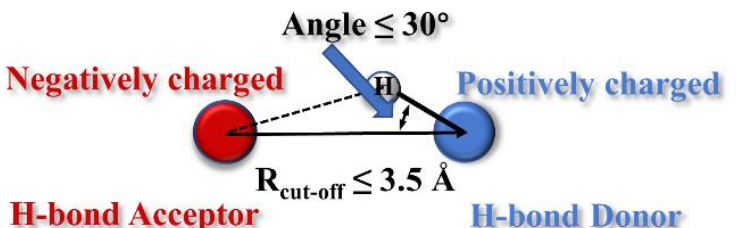

H-bond Donor

Figure S5: (A) The maximum distance for polar contact, i.e. the distance between positively charged atom and negatively charged atom, should be less than $\sim 6.0 \AA$. (B) The maximum distance between H-bond donor and acceptor should be less than $\sim 3.5 \AA$, and the angle should be less than $\sim 30^{\circ}$. 


\section{(A) $\alpha$-Helix template}

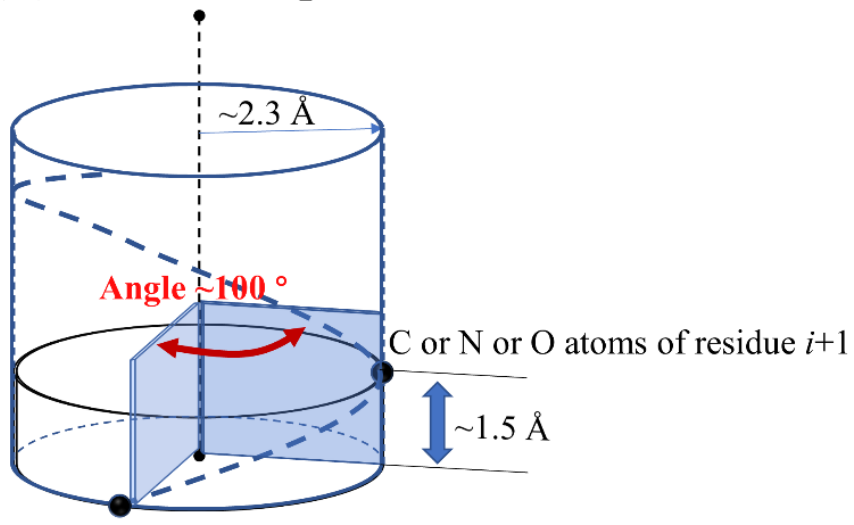

$\mathrm{C}$ or $\mathrm{N}$ or $\mathrm{O}$ atoms of residue $i$
(B) Reference model

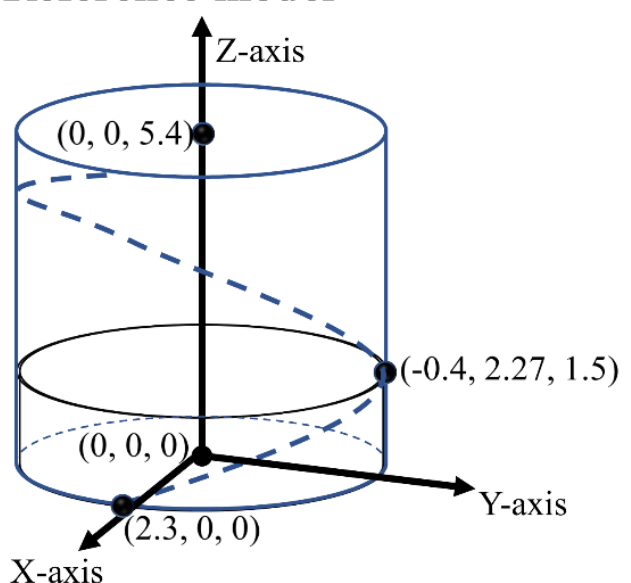

Figure S6: (A) The structural template of standard $\alpha$-helix: the residues are arranged in a righthanded helical structure and the rotation angle between residue $i$ and $i+1$ is $\sim 100^{\circ}$ with a rise of 1.5 $\AA$ along the helical axis; (B) A reference model is build based on the parameters of standard $\alpha$-Helix, and this model will be aligned to $\alpha 0 / \alpha 1$ helices of T4L L99A combined with the central axis.

\section{The complete structures of MEK1 during the loop-in and loop-out transition}

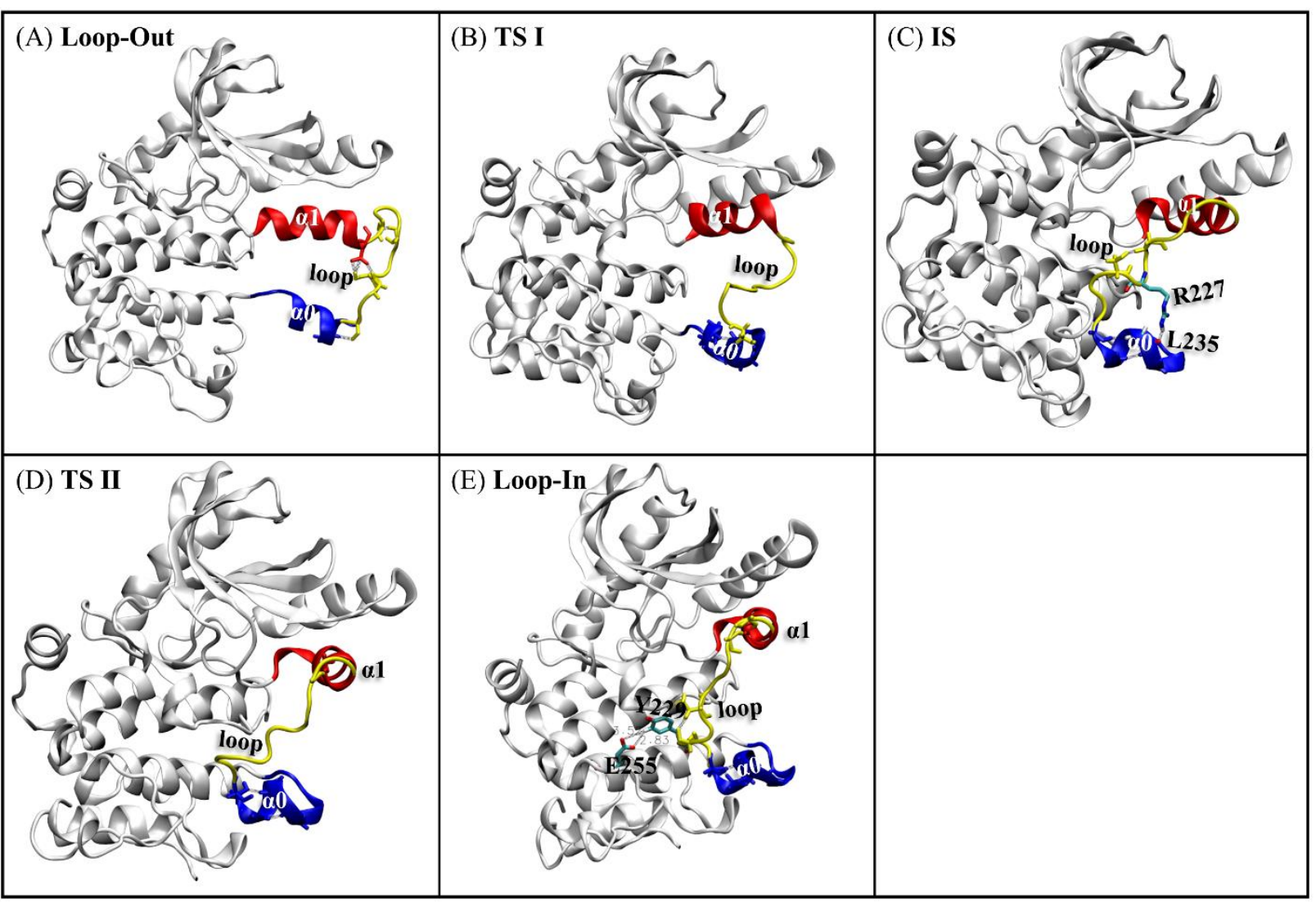

Figure S7: (A-G) Complete structures of MEK1 during the loop-in and loop-out transition, and the same ISs and TSs defined in Figure 6 are showed. 


\section{Supplemental references}

[1]. Eriksson, A. E.; Baase, W. A.; Wozniak, J. A.; Matthews, B. W. A cavity-containing mutant of T4 lysozyme is stabilized by buried benzene. Nature 1992, 355, 371-373.

[2]. Bouvignies, G.; Vallurupalli, P.; Hansen, D. F.; Correia, B. E.; Lange, O.; Bah, A.; Vernon, R. M.; Dahlquist, F. W.; Baker, D.; Kay, L. E. Solution structure of a minor and transiently formed state of a T4 lysozyme mutant. Nature 2011, 477, 111-114.

[3]. Fischmann, T. O.; Smith, C. K.; Mayhood, T. W.; Myers, J. E.; Reichert, J. P.; Mannarino, A.; Carr, D.; Zhu, H.; Wong, J.; Yang, R. S.; Le, H. V.; Madison, V. S. Crystal structures of MEK1 binary and ternary complexes with nucleotides and inhibitors. Biochemistry 2009, 48, 2661-2674.

[4]. Tyler, R. C.; Mrray, N. J.; Peterson, F. C.; Volkman, B. F. Native-state interconversion of a metamorphic protein requires global unfolding. Biochemistry 2011, 50, 7077-7079.

[5]. Harvey, S. R.; Porrini, M.; Konijnenberg, A.; Clarke, D. J.; Tyler, R. C.; Langridge-Smith, P. R. R.; MacPhee, C. E.; Volkman, B. F.; Barran, P. E. Dissecting the dynamic conformations of the metamorphic protein lymphotactin. J. Phys. Chem. B 2014, 118, 12348-12359.

[6]. Zhu, L. Z.; Sheong, F. K.; Cao, S. Q.; Liu, S.; Unarta, I. C.; Huang, X. TAPS: A traveling-salesman based automated path searching method for functional conformational changes of biological macromolecules. $J$. Chem. Phys. 2019, 150, 124105.

[7]. Hénin, J.; Chipot, C. Overcoming free energy barriers using unconstrained molecular dynamics simulations. J. Chem. Phys. 2004, 121, 2904-2914. 